\title{
Perfluorocarbons Decrease Chlamydophila pneumoniae-Mediated Inflammatory Responses of Rat Type II Pneumocytes In Vitro
}

\author{
HEIDE WISSEL, WOLFRAM BURKHARDT, JAN RUPP, ROLAND R. WAUER, AND MARIO RÜDIGER \\ Clinic for Neonatology [H.W., W.B., R.R.W., M.R.], Campus Charité Mitte, D-10098 Berlin, Germany; Clinic for Neonatology [M.R.], \\ Medical University Innsbruck, A-6020 Innsbruck, Austria; Institute of Medical Microbiology and Hygiene [J.R.], University of Lübeck,
} D-23560 Lübeck, Germany

\begin{abstract}
Chlamydophila pneumoniae alter the expression of Toll-like receptor (TLR) 4 in alveolar type II (ATII)-cells. Subsequently nuclear factor kappaB $(\mathrm{NF}-\kappa \mathrm{B})$ is activated and tumor necrosis factor- $\alpha$ (TNF- $\alpha$ ) and macrophage inflammatory protein 2 (MIP-2) are produced. Perfluorocarbons (PFC) are beneficial in animals with bacterial pneumonia and reduce production of TNF- $\alpha$. Using isolated ATII-cells, it was studied whether PFC prevent C. pneumoniae-induced TNF- $\alpha$ and MIP-2 release and what the underlying pathway is. PF5080 preincubation prevented C. pneumoniae-induced secretion of TNF- $\alpha(43 \pm 10$ versus $661 \pm 41$ $\mathrm{pg} / \mathrm{mL})$ and MIP-2 (573 \pm 41 versus $4786 \pm 502 \mathrm{pg} / \mathrm{mL})$. The C. pneumoniae-induced 2.2-fold increase of TNF- $\alpha$ Receptor 1 expression was reduced by PF5080. C. pneumoniae reduced cytoplasmatic $\mathrm{I} \kappa \mathrm{B} \alpha(3.7 \pm 0.3$ versus $14 \pm 1)$ and increased NF- $\kappa \mathrm{B}$ p65 $(31 \pm 7.5$ versus $3.6 \pm 1.1)$ compared with control. PF5080 prevented NF- $\kappa \mathrm{B}$ activation. TLR4 expression was 1.5 -fold higher after C. pneumoniae incubation, but remained at control levels after PF5080 pretreatment. After $24 \mathrm{~h}$ of C. pneumoniae incubation, in 88 $\pm 6 \%$ of cells bacteria were found in the perinuclear region and in $50 \%$ of these cells bacteria adhered to cellular surface. After PF5080 preincubation, $C$. pneumoniae were in $32 \pm 4 \%$ attached to and in $5 \pm 1 \%$ internalized in ATII-cells. Since PF5080 was found in ATII-cell membranes, PF5080 effect could be explained by an alteration of the cellular membrane, preventing activation of the inflammatory cascade. (Pediatr Res 60: 264-269, 2006)
\end{abstract}

Chlamydophila pneumoniae are obligate intracellular Gram-negative bacteria that cause respiratory infections in pediatric populations and adults $(1,2)$. Recent studies demonstrated the presence of $C$. pneumoniae in alveolar macrophages and ATII cells in patients with chronic obstructive pulmonary disease (COPD) (3). Whereas most respiratory infections with $C$. pneumoniae are self-limited (4), bacterial colonization can lead to infectious exacerbations and development of COPD (5). Because detection rate of C. pneumonia varies significantly (6), the clinical relevance of $C$. pneumoniae is still controversial.

The effect of C. pneumoniae on isolated ATII-cells is well characterized. C. pneumoniae inhibit the surfactant metabo-

Received February 24, 2006; accepted April 14, 2006.

Correspondence: Mario Rüdiger, M.D., Ph.D., Department of Neonatology, Medical University Innsbruck, Anichstr. 35, 6020 Innsbruck, Austria; e-mail: mario. ruediger@uibk.ac.at

This study was supported by grants Wi 2074/1-1 from the Deutsche Forschungsgemeinschaft and the "Medizinischer Forschungsfonds Tirol."

DOI: $10.1203 / 01 . p d r .0000233033 .82664 .91$ lism of ATII-cells after internalization (7). Many of C. pneumoniae-induced effects are mediated by cytokines. C. pneumoniae act at the ATII cell membrane to induce the expression of TLR4 (8). TLR signaling is partly mediated by the transcription factor NF- $\kappa \mathrm{B}$, which controls the expression of many genes involved in the inflammatory response (9). C. pneumoniae-induced activation of $\mathrm{NF}-\kappa \mathrm{B}$ leads to a release of the chemokine MIP-2 and the pro-inflammatory cytokine tumor necrosis factor alpha (TNF- $\alpha)$ (8) and its receptor tumor necrosis factor receptor 1 (TNFR1). Together, they play an important role in bacterial infections and modulate the inflammatory process (10).

PFC-administered as liquid (11), vapor (12), or gas (13) into the lung-represent an alternative approach to treat respiratory insufficiency. Intratracheal PFC application prolonged the survival of rats with bacterial pneumonia (14) and reduced the bacterial count in the lungs of newborn rabbits with connatal group B streptococcal pneumonia (15). Furthermore, PFC exhibit anti-inflammatory properties. In isolated cells, PFC prevent LPS-induced production of TNF- $\alpha(16,17)$. A similar effect is found in different animal models of lung injury (18-20). Thus, PFC represent a promising supplementary therapy in patients with pulmonary infections.

The pathway that mediates anti-inflammatory properties of PFC remains unknown. Initially, a "liquid-PEEP" (21-23) or a barrier function that prevents ligand receptor contact $(24,25)$ was proposed. But recent data suggest a direct interaction of PFC with intracellular pathways $(16,26)$ or a stabilizing effect on the cellular membrane (27).

The present study was performed on an established model of $C$. pneumoniae-mediated inflammation in isolated ATII cells. The aim was to test whether preincubation of isolated ATII cells with PFC prevents the $C$. pneumoniae-induced rise in inflammatory mediators. To elucidate mechanisms of PFC activity, intracellular steps that mediate the C. pneumoniaeinduced TNF- $\alpha$ release were studied in detail.

Abbreviations: ATII, alveolar type II; cHSP60, chlamydial Heat Shock Protein 60; CLSM, confocal laser scanning microscopy; MIP-2, macrophage inflammatory protein 2 ; NF- $\mathbf{\kappa B}$, nuclear factor kappaB; PFC, perfluorocarbons; TLR4, Toll-like receptor 4 


\section{MATERIALS AND METHODS}

Cell culturing. C. pneumoniae strain TW183 was cultured and purified as described (28). Isolation of rat ATII cells and incubation with $C$. pneumoniae were described in detail recently (8).

The 3-h adherent cells were preincubated with PF5080 (C6F18, molecular weight 438 , density $1.77 \mathrm{~g} / \mathrm{mL}$, viscosity $0.75 \mathrm{cSt}$, surface tension $15 \mathrm{mN} / \mathrm{m}$, vapor pressure 61 torr) that was obtained from 3M (Neuss, Germany) or with modified Eagle's medium (MEM) (PAA Laboratories GmbH, Linz, Austria) for $30 \mathrm{~min}$ at $37^{\circ} \mathrm{C}$. Thereafter, PFC or MEM was removed and ATII cells were incubated with $C$. pneumoniae at a concentration of 2 inclusion forming units (IFU) per cell. Time of $C$. pneumoniae incubation varied and is specified in the results section.

Viability of isolated ATII cells (assessed by trypan blue staining) was $>97 \%$ and remained above $92 \%$ after cell incubation with PF5080 and C. pneumoniae. Cell purity, estimated by hematoxylin staining, was $>90 \%$.

Western blot analysis. Nuclear and cytoplasmatic extracts and membrane fractions were prepared from cells as reported previously $(29,30)$. TNFR1 and TLR4 protein were assayed in membrane, $\mathrm{I} \kappa \mathrm{B} \alpha$ protein, and chlamydialHSP60 in cytoplasmatic and NF- $\kappa$ B p65 in nuclear extracts of ATII cells by Western blotting. Proteins (50 $\mu \mathrm{g}$ for TNFR1, TLR4, and cHSP60; $40 \mu \mathrm{g}$ for $\mathrm{I} \kappa \mathrm{B} \alpha ; 10 \mu \mathrm{g}$ for $\mathrm{p} 65)$ were mixed with $2 \times \mathrm{SDS}$ sample buffer, heated at $95^{\circ} \mathrm{C}$ for $5 \mathrm{~min}$, and separated by $10 \%$ (TLR4, p65) and $12.5 \%$ (TNFR-1, I $\kappa \mathrm{B} \alpha$, cHSP60) SDS-polyacrylamide gels. Separated proteins were blotted onto nitrocellulose membranes. Mouse IgG anti-cHSP60 (ALX-804-072-R100) antibodies (from ALEXIS Biochemicals, AXXORA GmbH, Grünberg, Germany) and rabbit IgG anti-TNFR1 (H-271) sc-7895, goat IgG anti-TLR4 (L-14) sc-16240, mouse monoclonal IgG anti-I $\kappa \mathrm{B} \alpha(\mathrm{H}-4)$ sc-1643, and rabbit IgG anti-NF- $\kappa$ B p65 (C-20) sc-372 antibodies (from Santa Cruz Biotechnology, Heidelberg, Germany) were used for primary detection. Peroxidaseconjugated anti-goat $\mathrm{IgG}$, anti-mouse $\mathrm{IgG}$, and anti-rabbit IgG antibodies (Dianova, Hamburg, Germany) were used for secondary detection. Protein bands were visualized by enhanced chemiluminescence (ECL) (Amersham Biosciences, Piscataway, NJ) and quantified by scanning densitometry (GS-710 Imaging Densitometer; Bio-Rad, Hercules, CA).

Immunocytochemistry and CLSM. For immunocytochemistry, isolated ATII cells were plated on glass cover slips for $3 \mathrm{~h}$ at $37^{\circ} \mathrm{C}$. Cells were preincubated with or without PF5080 for $30 \mathrm{~min}$ at $37^{\circ} \mathrm{C}$. Thereafter cells were incubated with $C$. pneumoniae, fixed in $1 \%$ paraformaldehyde $/ 250 \mathrm{mM}$ HEPES ( $\mathrm{pH} 7.4$ ) and permeabilized with $0.04 \%$ saponin as described (8). For staining of TNFR1 and TLR4 cells were incubated with rabbit IgG antiTNFR1 (H-271) and goat IgG anti-TLR4 (L-14) (Santa Cruz Biotechnology) for $20 \mathrm{~h}$ at $4^{\circ} \mathrm{C}$. To stain the NF- $\kappa \mathrm{B}$ subunits, the following antibodies were used: MAb anti-I $\kappa \mathrm{B} \alpha(\mathrm{H}-4)$ (Santa Cruz Biotechnology) and MAb anti$\mathrm{NF}-\kappa \mathrm{B}$ p65 subunit (3026), recognizing predominantly p65 when $\mathrm{I} \kappa \mathrm{B} \alpha$ is not bound to p65 (Chemicon, Hofheim, Germany). To stain C. pneumoniae, cells were incubated with $\mathrm{MAb}$ against major outer membrane protein 1 (MOMP-1) of C. pneumoniae (DakoCytomation, Hamburg, Germany). To identify ATII cells, MAb antibody 3C9 was used against the 180-kDa lamellar body-limiting membrane protein (Berkeley Antibody, Richmond, VA).

Thereafter, cells were incubated with one of the secondary antibodies: Alexa 594 anti-goat IgG, anti-mouse IgG labelled with Alexa 488 or Alexa 594, anti-rabbit IgG labeled with Alexa 594 (Molecular Probes Europe BV, Leiden, Netherlands) for $2 \mathrm{~h}$ at $22^{\circ} \mathrm{C}$. F-actin cytoskeleton, Alexa 488conjugated phalloidin (Molecular Probes, Eugene, OR) was used ( $2 \mathrm{~h}$ at $22^{\circ} \mathrm{C}$ ). Nuclear DNA was stained with $4^{\prime}, 6$-diamidino-2-phenylindole (DAPI) (Molecular Probes) for $20 \mathrm{~min}$.

Staining was analyzed with a Zeiss laser scanning microscope LSM 510 META with Axiovert 200 M (Carl Zeiss Jena GmbH, Jena, Germany) as described (8). Images were taken using a Plan-Apochromat $63 \times / 1.4$ oil immersion objective and fluorescence excitation at $488 \mathrm{~nm}$ (30 mW Ar laser), $543 \mathrm{~nm}$ (1 mW HeNe laser), and $405 \mathrm{~nm}$ (diode laser). To minimize signal crosstalk, a sequential scan with fast change of excitation lines was performed.

Semi-quantitative estimation of NF- $\kappa \mathrm{B}$ subunits was performed as described (8). Thirty randomly chosen cells from six different regions were analyzed with a Zeiss LSM 510 system. Confocal settings were maintained for all images. Images were recorded with a scanning speed at $8 \mathrm{~s} /$ frame with a resolution of $512 \times 512$ pixels. Serial sections of cells $(\mathrm{z}$ stack) at a depth of $0.5 \mu \mathrm{m}$ were performed. Fluorescence intensity was determined on confocal images using a computer-based image analysis system (MetaView; Visitron Systems GmbH, Puchheim, Germany) by measuring average intensity per pixel within a fixed-area of the relevant cellular area.

TNF- $\alpha$ and MIP-2 ELISA. Three-hour adherent ATII cells on plastic dishes were preincubated with PF5080 followed by incubation with $C$. pneumoniae for 3 or $6 \mathrm{~h}$. Cell culture supernatants were collected and analyzed for TNF- $\alpha$ after $3 \mathrm{~h}$ and for MIP-2 after $6 \mathrm{~h}$ secretion by ELISA. TNF- $\alpha$ concentration was determined by rat TNF- $\alpha$ Quantikine ELISA (R\&D Systems Inc, Minneapolis, MN) and MIP-2 concentration by rat MIP-2 ELISA kit (Biosource Europe, Nivelles, Belgium).

Intratracheal administration of PF5080. To study intracellular PFCdistribution, PF5080 was labeled with 4,4-difluoro-2,6-di-t-butyl-1,3,5,7,8pentam, ethyl-4bora-3a, 4a-diaza-s-indacene (FEW Chemicals GmbH, Wolfen, Germany) as described (31). Isolated ATII cells were incubated with labeled PF5080 for $20 \mathrm{~min}$ and analyzed by confocal microscopy. To study PFC uptake in vivo, male Wistar rats were anesthetized with a mixture of ketamine $(10 \mathrm{mg} / \mathrm{kg})$ and pentobarbital natrium $(20 \mathrm{mg} / \mathrm{kg})$ intraperitoneally. A tube with side port for intratracheal administration of PFC was inserted via tracheostomy. After intratracheal application of labeled PFC animals were ventilated for 10 min (31) and, thereafter, lungs were fixed with $3 \%$ neutral buffered formalin for $48 \mathrm{~h}$. Fixed lungs were paraffin-embedded and cut into sections of $4 \mu \mathrm{m}$. Tissue distribution of labeled PF5080 was analyzed with CLSM. The animal study was approved by the local animal care and use committee, handling of animals was in accordance with the guidelines.

Statistics. Statistical comparisons were performed by ANOVA with subsequent Fisher's protected least significant difference (PLSD) test. The level of significance was set at $p<0.05$.

\section{RESULTS}

PF5080 reduce $C$. pneumoniae-mediated TNF- $\alpha$ and MIP-2 release. Adherent ATII cells were preincubated with PF5080 followed by $C$. pneumoniae. TNF- $\alpha$ concentration in the supernatant was measured after $3 \mathrm{~h}$ (Fig. $1 \mathrm{~A}$ ) and MIP-2 concentration after $6 \mathrm{~h}$ incubation with $C$. pneumoniae (Fig. 1B).

Whereas the TNF- $\alpha$ concentration of control cells was only $21 \pm 8 \mathrm{pg} / \mathrm{mL}$, a significantly $(p<0.0001)$ higher TNF- $\alpha$ concentration was found after $C$. pneumoniae incubation $(661 \pm 41 \mathrm{pg} / \mathrm{mL})$. Preincubation with PF5080 prevented the C. pneumoniae-induced increase in TNF- $\alpha(43 \pm 10 \mathrm{pg} / \mathrm{mL})$. Similar results were found for MIP-2. The MIP-2 concentration in supernatant of $C$. pneumoniae-incubated cells was significantly higher than in control cells $(4786 \pm 501 \mathrm{pg} / \mathrm{mL}$ versus $205 \pm 82 \mathrm{pg} / \mathrm{mL}$ ). PF5080 preincubation prevented the C. pneumoniae-induced MIP-2 production $(573 \pm 41 \mathrm{pg} / \mathrm{mL})$.

PF5080 decrease C. pneumoniae-mediated TNFR1 expression. Because TNF- $\alpha$ mainly acts via the TNFR 1 , the effect of PF5080 on the TNFR1 expression was studied.

Confocal imaging revealed an increased expression of TNFR1 in response to $C$. pneumoniae after $3 \mathrm{~h}$ of incubation when compared with control cells. Almost no increase in the TNFR1 expression was found in cells that were preincubated with PF5080 and thereafter exposed to C. pneumoniae (Fig. 2A).

The amount of TNFR1 was quantified by Western blot analysis (Fig. 2, $B$ and $C$ ). Incubation of ATII cells with
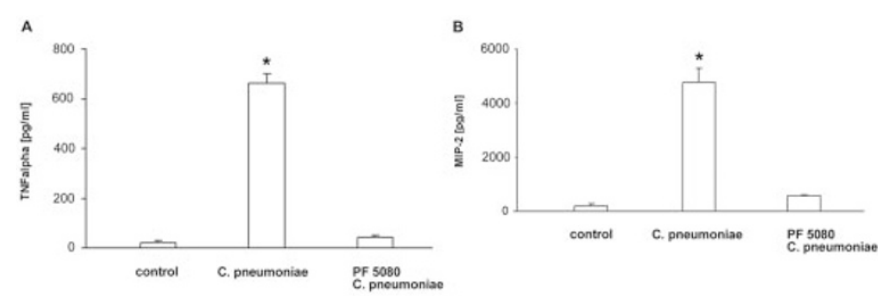

Figure 1. PF5080 reduce $C$. pneumoniae-mediated TNF- $\alpha$ and MIP-2 release $(A)$ TNF- $\alpha$ and $(B)$ MIP-2 concentration in the supernatant of ATII cells (control), nontreated and pretreated with PF5080 followed by $C$. pneumoniae incubation for 3 (TNF- $\alpha$ ) or 6 (MIP-2) h. Shown are mean \pm SD in pg/mL of $n=3$ experiments, asterisk indicates $p<0.0001$. 
A

control
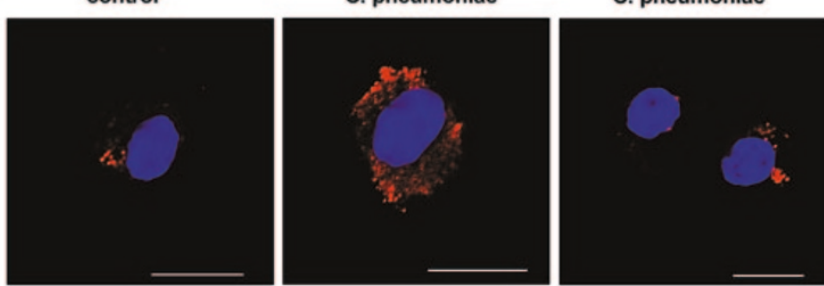

B

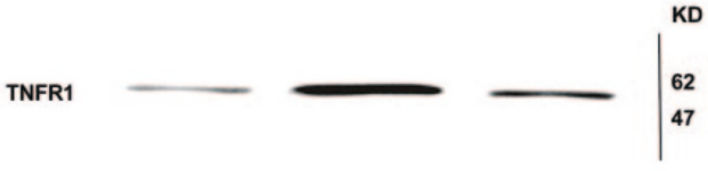

C

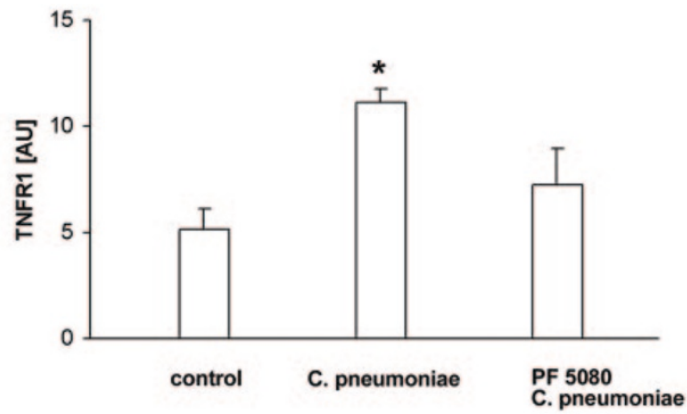

Figure 2. PF5080 decrease $C$. pneumoniae-mediated TNFR1 expression. (A) Representative CLSM images of untreated (control) and $C$. pneumoniae incubated ( $3 \mathrm{~h}$ ) ATII cells without and with PF5080 pretreatment. TNFR1 (red) and nuclear DNA (blue), the bar equals $10 \mu \mathrm{m}$. ( $B$ and $C$ ) TNFR1 concentration analyzed by Western blot. Shown are mean \pm SD in arbitrary units (AU) of $n=3$ experiments, asterisk indicates $p<0.001$.

C. pneumoniae caused a 2.2-fold increase in TNFR1 expression when compared with control cells. In contrast, PF5080 reduced $C$. pneumoniae-mediated TNFR1 expression.

PF5080 reduce $C$. pneumoniae-mediated $N F-\kappa B$ activation. NF- $\kappa \mathrm{B}$ represents a key mediator in the process of C. pneumoniae-induced activation of TNF- $\alpha$. Therefore, the effect of PF5080 on the C. pneumoniae-mediated NF- $\kappa \mathrm{B}$ activation was studied (Fig. 3, $A$ and $B$ ).

In noninfected control cells, $\mathrm{I} \kappa \mathrm{B} \alpha$ was located in the cytoplasm $(71.3 \pm 4.6)$. After $30 \mathrm{~min}$ of $C$. pneumoniae incubation, the concentration of cytoplasmatic $\mathrm{I} \kappa \mathrm{B} \alpha$ was significantly reduced $(29.5 \pm 1.2)$. The $C$. pneumoniae-mediated decrease of $\mathrm{I} \kappa \mathrm{B} \alpha$ was prevented by a preincubation with PF5080 (65.9 \pm 3.8).

Staining with an anti-p65 antibody (recognizes p65 only when $\mathrm{I} \kappa \mathrm{B} \alpha$ is not bound to p65) showed an activation of p65 in the nucleus after $30 \mathrm{~min}$ of $C$. pneumoniae incubation $(179 \pm 21)$. Similar to noninfected control cells $(6.1 \pm 2)$ almost no activation of p65 was found in the nucleus of C. pneumoniae incubated cells that were pretreated with PF5080 (9.1 \pm 1.6$)$. In PF5080 pretreated cells without any subsequent $C$. pneumoniae incubation no $\mathrm{I} \kappa \mathrm{B} \alpha$ decrease nor p65 activation was found.

The amount of cytoplasmatic $\mathrm{I} \kappa \mathrm{B} \alpha$ and of nuclear p65 was quantified by Western blot analysis (Fig. 3, $C$ and $D$ ). After $C$. pneumoniae incubation cytoplasmatic $\mathrm{I} \kappa \mathrm{B} \alpha$ protein
A

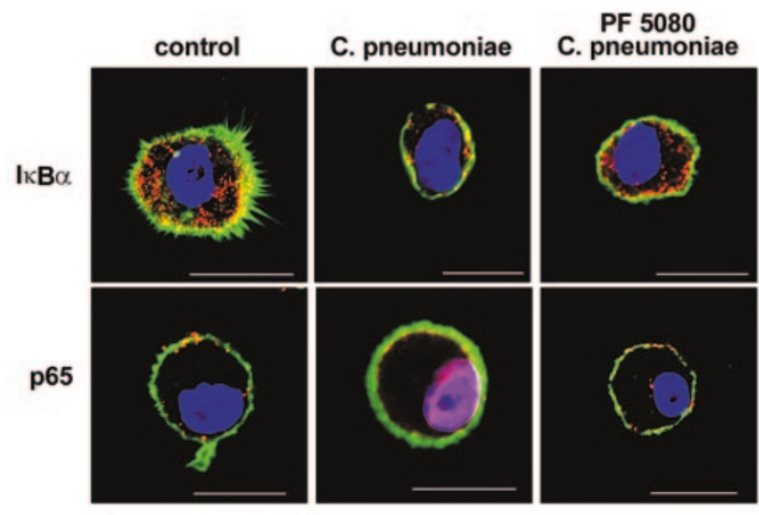

B

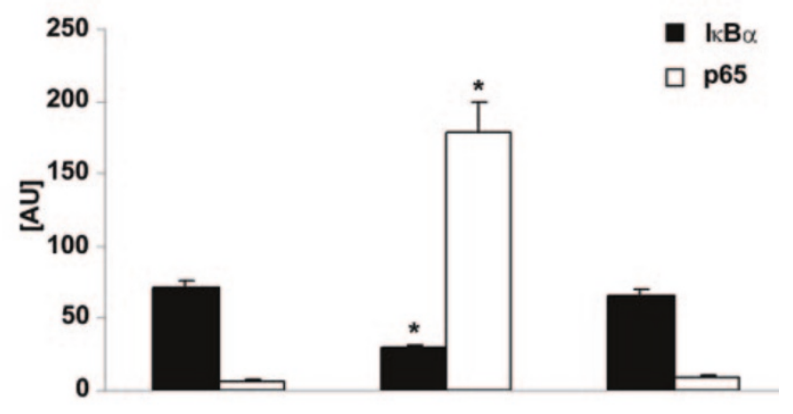

C
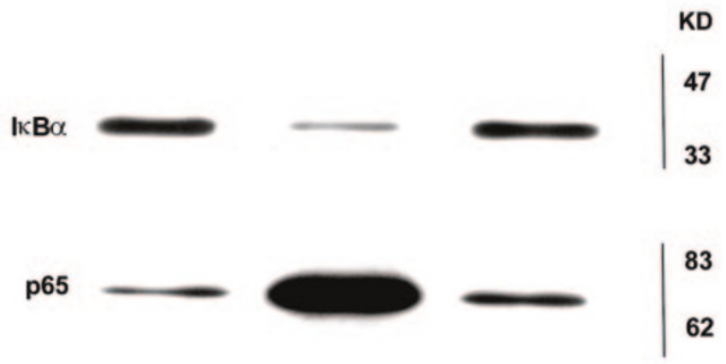

D

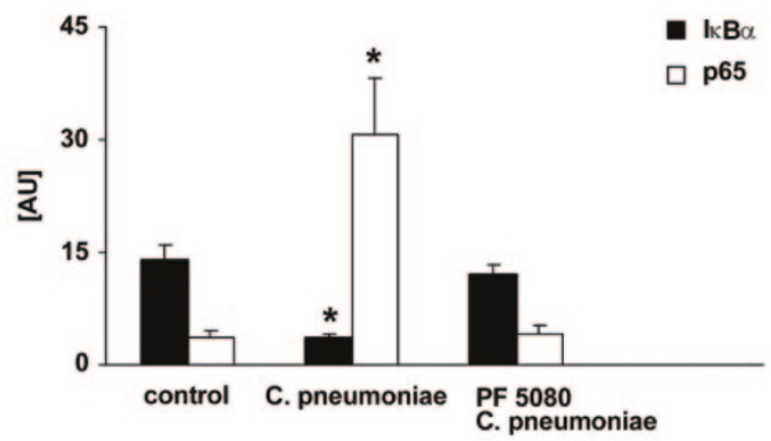

Figure 3. PF5080 reduce $C$. pneumoniae-mediated NF- $\kappa \mathrm{B}$ activation. $(A$ and $B)$ Representative CLSM images of untreated (control) and $C$. pneumoniae-incubated (30 min) ATII cells without and with PF5080 pretreatment. I $\kappa \mathrm{B} \alpha$ and p65 (red), F-actin cytoskeleton (green), and nuclear DNA (blue); areas of blue-red overlap are pink; the bar equals $10 \mu \mathrm{m}$. Cytoplasmatic I $\kappa \mathrm{B} \alpha$ and nuclear NF- $\kappa \mathrm{B}$ p65 were quantified on confocal images. Shown are mean \pm SD in arbitrary units (AU) of $n=3$ experiments, asterisk indicates $p<0.0001$ for $\mathrm{I} \kappa \mathrm{B} \alpha$ in cytoplasm and $p<$ 0.0001 for p65 in nucleus. ( $C$ and $D$ ) Cytoplasmatic $\mathrm{I} \kappa \mathrm{B} \alpha$ and nuclear p65 were quantified by Western blot. Shown are mean \pm SD in arbitrary units (AU) of $n=3$ experiments, asterisk indicates $p<0.0001$ for $\mathrm{I} \kappa \mathrm{B} \alpha$ in cytoplasm and $p<0.0001$ for p65 in nucleus. 
was significantly lower $(3.7 \pm 0.3$ versus $14 \pm 2)$ and nuclear p65 protein concentration was significantly higher $(31 \pm 7.5$ versus $3.6 \pm 1.1$ ) than in control cells. Pretreatment of cells with PF5080 prevented the $C$. pneumoniae induced decrease in $\mathrm{I} \kappa \mathrm{B} \alpha(12.2 \pm 1)$ and increase in p65 (4 \pm 1.3$)$.

PF5080 decrease C. pneumoniae-mediated TLR4 expression. $C$. pneumoniae interact with the TLR 4 of ATII cells to activate the intracellular cascade that leads to TNF- $\alpha$ secretion. The effect of PF5080 on these changes in TLR4 were studied.

Whereas C. pneumoniae incubation is associated with a mobilization of TLR4 from the cytoplasm to the external cell surface and a subsequent increase in TLR4 expression, preincubation of cells with PF5080 prevented the increase in TLR4 expression (Fig. 4A).

The amount of TLR4 protein was measured by Western blot analysis (Fig. 4B) and quantified (Fig. 4C). The TLR4 protein expression was significantly (1.5-fold) higher in $C$. pneumoniae-exposed cells when compared with control cells. TLR4 expression in PF5080-pretreated cells followed by incubation with $C$. pneumoniae remained at control levels.

In ATII cells that were incubated with PF5080 but not C. pneumoniae, the TLR4 expression remained at the low level of noninfected (control) cells.
A
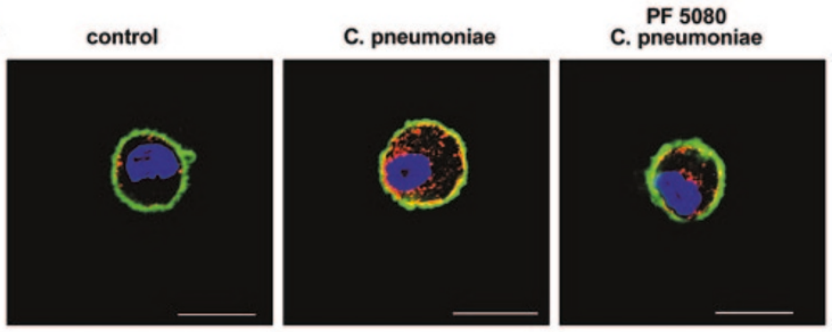

B

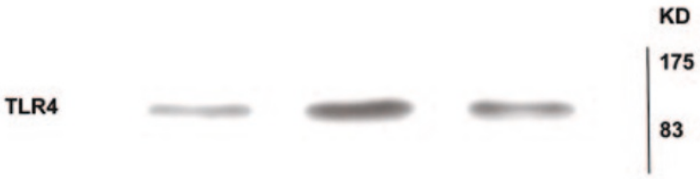

C

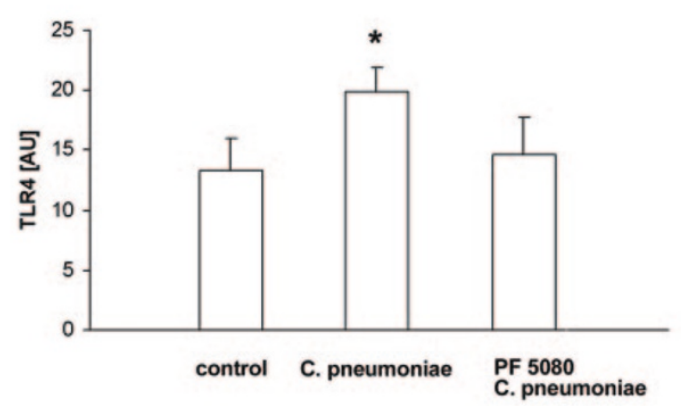

Figure 4. PF5080 decrease C. pneumoniae-mediated TLR4 expression. (A) Representative CLSM images of untreated (control) and $C$. pneumoniae incubated $(30 \mathrm{~min}$ ) ATII cells without and with PF5080 pretreatment. TLR4 (red), F-actin cytoskeleton (green), nuclear DNA (blue); areas of overlap between red and green are yellow; the bar equals $10 \mu \mathrm{m}$. ( $B$ and $C$ ) TLR4 concentration was analyzed by Western blot. Shown are mean \pm SD in arbitrary units (AU) of $n=4$ experiments, asterisk indicates $p<0.0001$.
PF5080 reduce the C. pneumoniae contact with ATII pneumocytes. Since pretreatment of ATII-cells with PF5080 prevented $C$. pneumoniae-induced effects, we evaluated whether preincubation affects the adherence and internalization of $C$. pneumoniae. ATII cells were pretreated with PF5080 (30 min), followed by C. pneumoniae incubation (24 h). Bacteria were detected with an anti- $C$. pneumoniae MOMP-specific antibody. Furthermore, the F-actin cytoskeleton and the nuclear DNA were stained (Fig. 5A).

In control (uninfected) cells, no bacteria were identified. In cells incubated with $C$. pneumoniae in the absence of PF5080, bacteria were found in the perinuclear region of $88 \pm 6 \%$ all ATII cells and in $50 \%$ of these cells bacteria were adherent to cell surface. In $12 \pm 5 \%$ of cells bacteria were neither adherent nor internalized.

After pretreatment with PF5080, bacteria were adherent to the cell surface in $32 \pm 4 \%$ of cells. However, only in about $5 \pm 1 \%$ cells bacteria were found in the perinuclear region. In

A
A control

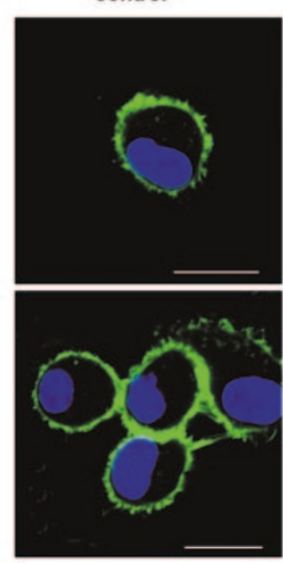

C. pneumoniae

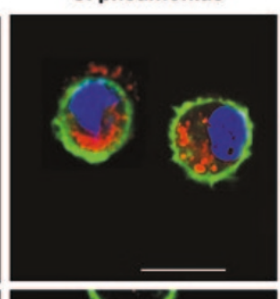

PF 5080 C. pneumoniae

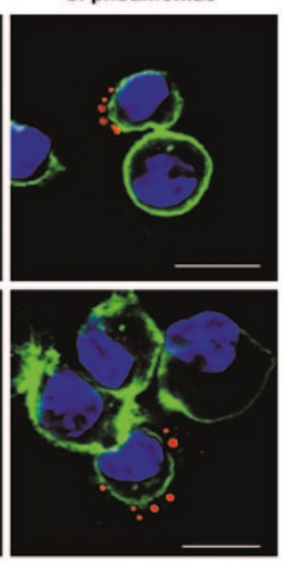

B

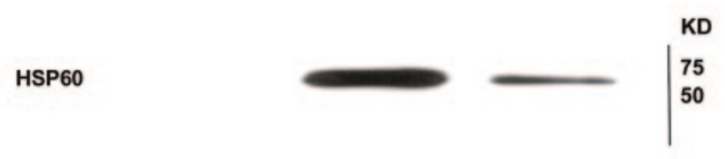

C

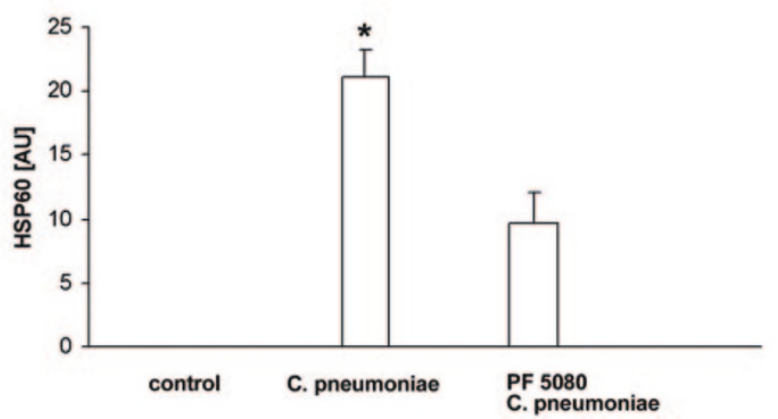

Figure 5. PF5080 reduce the $C$. pneumoniae contact with type II pneumocytes. (A) Representative CLSM images of untreated (control) and C. pneumoniae-incubated $(24 \mathrm{~h})$ ATII cells without and with PF5080 pretreatment. Nuclear DNA (blue), F-actin cytoskeleton (green), C. pneumoniae (red); the bar equals $10 \mu \mathrm{m}$. ( $B$ and $C$ ) Chlamydial HSP60 concentration was analyzed by Western blot technique. Shown are mean \pm SD in arbitrary units (AU) of $n=4$ experiments, asterisk indicates $p<0.0001$. 
the majority of cells $(63 \pm 4 \%)$ bacteria were neither adherent nor internalized.

The concentration of cHSP60 was analyzed by Western blot analysis and quantified after $24 \mathrm{~h}$ of $C$. pneumoniae incubation (Fig. 5, $B$ and $C$ ). In uninfected ATII cells, no cHSP60 was detected. Expression of cHSP60 was significantly enhanced after $24 \mathrm{~h}$ of $C$. pneumoniae incubation. Preincubation of ATII cells with PF5080 partially prevented the C. pneumoniaeinduced increase in cHSP60.

PF5080 internalize in lamellar bodies and membrane structures of ATII cells. Finally, isolated ATII cells were incubated with labeled PF5080 to study whether PF5080mediated effects are caused by PFC incorporation into cellular membranes. The labeling was found in lamellar bodies and the cellular membrane (Fig. 6A).

After intratracheal instillation of labeled PF5080, an intensive staining was detected in cellular membranes of alveolar epithelial cells (Fig. 6B).

\section{DISCUSSION}

C. pneumoniae induce an inflammatory reaction in alveolar type II cells (8). PFC exhibit anti-inflammatory properties and have a beneficial effect in animal models of bacterial infection $(14,15)$. Thus, intratracheal PFC application could be a promising supplementary therapy for patients with bacterial infections. However, the mechanism of PFC activity is still poorly understood.

This study shows that incubation of isolated ATII-cells prevents the $C$. pneumoniae-induced production of the proinflammatory cytokine TNF- $\alpha$ as well as its receptor TNFR1 and chemokine MIP-2. PFC have been shown before to prevent the TNF- $\alpha$ production of either isolated cells or in animal models of lung injury $(12,16)$.

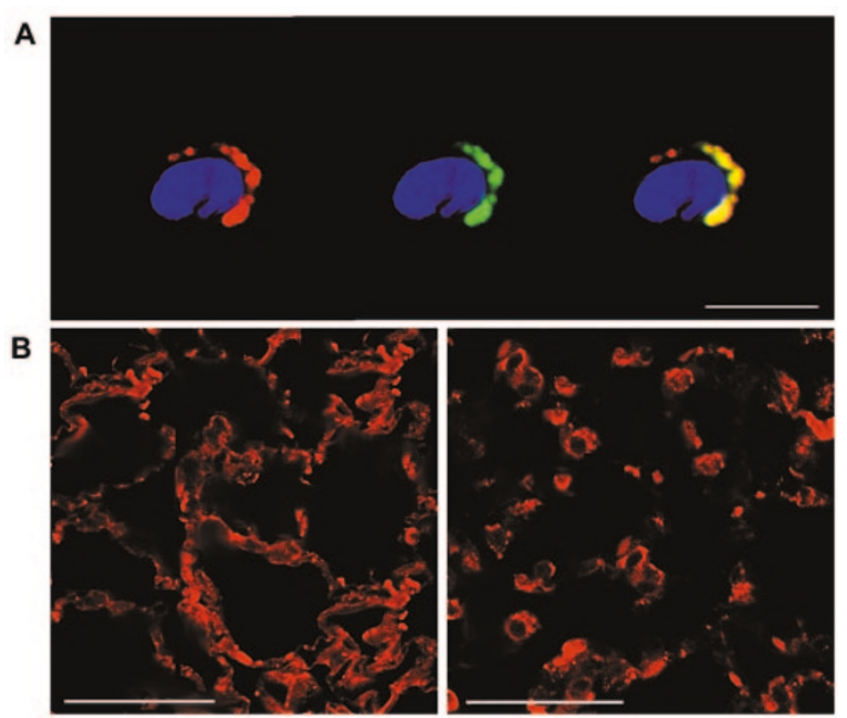

Figure 6. PF5080 internalize in lamellar bodies and membrane structures of ATII cells. (A) Representative CLSM images of ATII cells after incubation with labeled PF5080 (red) for $10 \mathrm{~min}$. Lamellar bodies were stained with MAb 3C9 (green), nuclear DNA (blue); areas of overlap between red and green are yellow; the bar equals $10 \mu \mathrm{m}$. (B) Representative CLSM images of rat lung after intratracheal instillation of labeled PF5080. Red-labeled PF5080 is found in membranes of ATII cells; the bar equals $50 \mu \mathrm{m}$.
In the present study, for the first time, the underlying pathway has been studied in detail. PF5080 prevented the C. pneumoniae-induced activation of NF- $\kappa \mathrm{B}$. Furthermore, after PF5080 incubation, the expression of TLR4 did not increase in the presence of $C$. pneumoniae. Consequently, after PF5080 incubation in only 5\% of ATII cells, C. pneumoniae were found internalized and in only $34 \%$ attached to the cellular surface.

The most likely explanation of the PFC effect is the integration of the lipophilic PFC into lamellar bodies and the cellular membrane as shown in the present study for ATII cells. A similar effect has been previously described for lamellar bodies (31) and for erythrocytes (27). Therefore, a PFC induced stabilization of cellular membranes (27) is the most likely explanation how PFC prevent the internalization of $C$. pneumoniae.

Extracellular $C$. pneumoniae require an intact host cell surface for attachment and subsequent activation of specific cell signaling pathways (32). We have recently shown that contact of $C$. pneumoniae with microvilli of ATII cells induces calcium-dependent changes in F-actin/ $\beta$-tubulin cytoskeleton involved in NF- $\kappa \mathrm{B}$ activation (33). C. pneumoniae appear to use several mechanism to enter host cells, including receptor-mediated endocytosis. Recently, a mannose 6-phosphate/IGF-II receptor was shown to enhance infection of endothelial cells by $C$. pneumoniae (34).

We demonstrated that constitutively expressed TLR4 in type II pneumocytes responds rapidly to $C$. pneumoniae contact and mediates the cellular responses to $C$. pneumoniae at a post-transcriptional level. The $C$. pneumoniae-induced $\mathrm{NF}-\kappa \mathrm{B}$ activation was reduced by a blockade of the TLR4 receptor (5). Either $C$. pneumoniae contact or the cHSP60 induce a TLR-mediated translocation of NF- $\kappa \mathrm{B}$ and a secretion of cytokines (35-38).

In the present study, PFC did not entirely prevent the adherence of $C$. pneumoniae to ATII cells. However, PFC did prevent the internalization of bacteria. However, there was no significant $C$. pneumoniae-induced NF- $\kappa \mathrm{B}$ activation or TNF- $\alpha$ secretion in PFC-pretreated cells.

It could be assumed that PFC directly alter the cellular surface membrane (including its receptor molecules and the $\mathrm{NF}-\kappa \mathrm{B}$ complex), thereby reducing the intracellular signalling cascade and the subsequent inflammation. The present data are confirmed by a study, showing that PFC treatment in lung of respiratory syncytial virus-infected mice reduced inflammatory activity by blocking the activation of the NF- $\kappa \mathrm{B}$ activation (19). Thus, it can be concluded that PFC do not only provide a mechanical or physical barrier, but do alter signaling pathway programs of host cells and thus influence intracellular processes.

The present data seem to support the idea to use PFC (e.g. by inhalation) within the treatment concept of $C$. pneumoniae infection. However, the present study has two limitations that require further investigation.

First of all, we did only study the effect of an incubation of ATII-cells with PFC prior to $C$. pneumoniae exposure. At the moment, there are no data available to show the effect of PFC on ATII-cells with internalized C. pneumoniae. 
Secondly, further studies are needed to verify the shown in vitro effect in vivo as well. We have previously shown that PF5080 does not have an impact on bacterial growth of group B streptococci in vitro (39). However, in vivo data on preterm rabbits with connatal GBS pneumonia show a reduced amount of GBS in the lungs of PF5080-treated animals (15). Therefore, the protective effect of the present study on isolated ATII cells could be even more pronounced in an animal model of C. pneumoniae infection.

In the past, clinical studies failed to show a benefit of partial liquid ventilation when compared with conventional therapy of severe respiratory failure. Nevertheless, liquid ventilation still represents a promising therapy, however, prior to a future clinical application, the molecular mechanism of PFC activity has to be better understood. The present study provides some further insight in the complex process of anti-inflammatory activity of PFC and will thus help to use PFC in a clinical setting more appropriate in the future.

Acknowledgments. The authors thank Ruth Herrmann and Silke Wilitzki (Clinic of Neonatology, Campus Charité Mitte, University Children's Hospital, Humboldt-University Berlin, Germany) Petra Klein (Institute of Biology, Department of Membrane Physiology, Humboldt University Berlin, Germany), and Anke Hellberg (Institute of Medical Microbiology and Hygiene, University of Luebeck, Luebeck, Germany) for technical assistance.

\section{REFERENCES}

1. Hammerschlag MR 2003 Pneumonia due to Chlamydia pneumoniae in children: epidemiology, diagnosis, and treatment. Pediatr Pulmonol 36:384-390

2. Jantos CA, Wienpahl B, Schiefer HG, Wagner F, Hegemann JH 1995 Infection with Chlamydia pneumoniae in infants and children with acute lower respiratory tract disease. Pediatr Infect Dis J 14:117-122

3. Rupp J, Droemann D, Goldmann T, Zabel P, Solbach W, Vollmer E, Branscheid D, Dalhoff K, Maass M 2004 Alveolar epithelial cells type II are major target cells for C. pneumoniae in chronic but not in acute respiratory infection. FEMS Immunol Med Microbiol 41:197-203

4. Boman J, Hammerschlag MR 2002 Chlamydia pneumoniae and atherosclerosis: critical assessment of diagnostic methods and relevance to treatment studies. Clin Microbiol Rev 15:1-20

5. Branden E, Koyi H, Gnarpe J, Gnarpe H, Tornling G 2005 Chronic Chlamydia pneumoniae infection is a risk factor for the development of COPD. Respir Med 99:20-26

6. Hammerschlag MR 2000 Chlamydia pneumoniae and the lung. Eur Respir J 16:1001-1007

7. Wissel H, Schulz C, Rüdiger M, Krüll M, Stevens PA, Wauer RR 2003 Chlamydia C. pneumoniae affect surfactant trafficking and secretion due to changes of type II cell cytoskeleton. Am J Respir Cell Mol Biol 29:303-313

8. Wissel H, Schulz C, Koehne P, Richter E, Maass M, Rudiger M 2005 Chalmydophila pneumoniae induces expression of TLR4 and release of TNF $\alpha$ and MIP-2 via an NF- $\kappa$ B pathway in rat type II pneumocytes. Respir Res 6:51-

9. Akira S, Takeda K, Kaisho T 2001 Toll-like receptors critical proteins linking innate and acquired immunity. Nat Immunol 2:675-680

10. Campbell LA, Nosaka T, Rosenfeld ME, Yaraei K, Kuo C 2005 Tumor necrosis factor alpha plays a role in the acceleration of atherosclerosis by Chlamydia pneumoniae in mice. Infect Immun 73:3164-3165

11. Shaffer TH, Wolfson MR, Greenspan JS, Hoffman RE, Davis SL, Clark LCJr 1996 Liquid ventilation in premature lambs: uptake, biodistribution and elimination of perfluorodecalin liquid. Reprod Fertil Dev 8:409-416

12. von der Hardt K, Schoof E, Kandler MA, Dötsch J, Rascher W 2002 Aerosolized perfluorocarbon suppresses early pulmonary inflammatory response in a surfactantdepleted piglet model. Pediatr Res 51:177-182

13. Bleyl JU, Ragaller M, Tschö U, Regner M, Kanzow M, Hübler M, Rasche S, Albrecht M 1999 Vaporized perfluorocarbon improves oxygenation and pulmonary function in an ovine model of acute respiratory distress syndrome. Anesthesiology 91:461-469

14. Dickson EW, Heard SO, Chu B, Fraire A, Brueggemann A, Doern GV 1998 Partial liquid ventilation with perfluorocarbon in the treatment of rats with lethal pneumococcal pneumonia. Anesthesiology 88:218-223
15. Rüdiger M, Some M, Jarstrand C, Calkovska A, Linderholm B, Robertson B, Herting E 2003 Influence of partial liquid ventilation on bacterial growth and alveolar expansion in newborn rabbits with group B-streptococcal pneumonia. Pediatr Res 54:808-813

16. Koch T, Ragaller M, Haufe M, Hofer A, Grosser M, Albrecht DM, Kotzsch M, Luther T 2001 Perfluorohexane attenuates proinflammatory and procoagulatory response of activated monocytes and alveolar macrophages. Anesthesiology 94:101109

17. Thomassen MJ, Buhrow LT, Wiedemann HP 1997 Perflubron decreases inflammatory cytokine production by human alveolar macrophages. Crit Care Med 25:20452047

18. Merz U, Klosterhalfen B, Häusler M, Kellinghaus M, Peschgens T, Hörnchen $H$ 2002 Partial liquid ventilation reduces release of leukotriene B4 and interleukin-6 in bronchoalveolar lavage in surfactant-depleted newborn pigs. Pediatr Res 51:183189

19. Haeberle HA, Nesti F, Dietrich HJ, Gatalica Z, Garofalo RP 2002 Perflubron reduces lung inflammation in respiratory syncytial virus infection by inhibiting chemokine expression and nuclear factor-kB activation. Am J Respir Crit Care Med 165:14331438

20. Kawamae K, Pristine G, Chiumello D, Tremblay LN, Slutsky A 2000 Partial liquid ventilation decreases serum tumor necrosis factor-a concentration in a rat aspiration lung injury model. Crit Care Med 28:479-483

21. Colton DM, Hirschl RB, Johnson KJ, Till GO, Dean SB, Bartlett RH 1994 Neutrophil infiltration is reduced during partial perfluorocarbon liquid ventilation in the setting of lung injury. Surg Forum 1055:668-670

22. Colton DM, Till GO, Johnson KJ, Dean SB, Bartlett RH, Hirschl RB 1998 Neutrophil accumulation is reduced during partial liquid ventilation. Crit Care Med 26:1716-1724

23. Colton DM, Till GO, Johnson KJ, Gater JJ, Hirschl RB 1998 Partial liquid ventilation decreases albumin leak in the setting of acute lung injury. $\mathrm{J}$ Crit Care 13:136-139

24. Baba A, Kim Y-K, Zhang H, Liu M, Slutsky AS 2000 Perfluorocarbon blocks tumor necrosis factor- $\alpha$-induced interleukin- 8 release from alveolar epithelial cells in vitro. Crit Care Med 28:1113-1118

25. Varani J, Hirschl RB, Dame M, Johnson K 1996 Perfluorocarbon protects lung epithelial cells from neutrophil-mediated injury in an in vitro model of liquid ventilation therapy. Shock 6:339-344

26. Haufe D, Luther T, Kotzsch M, Knels L, Koch T 2004 Perfluorocarbon attenuates response of concanavalin A-stimulated mononuclear blood cells without altering ligand-receptor interaction. Am J Physiol Lung Cell Mol Physiol 287:L210-L216

27. Obraztsov VV, Neslund G, Kornbrust E, Flaim S, Woods CM 2000 In vitro cellular effects of perfluorochemicals correlate with their lipid solubility. Am J Physiol Lung Mol Cell Physiol 278:L1018-L1024

28. Maass M, Harig U 1995 Evaluation of culture conditions used for isolation of Chlamydia pneumoniae. Am J Clin Pathol 103:141-148

29. Altavilla D, Saitta A, Guarini S, Galeano M, Squadrito G, Cucinotta D, Santamaria LB, Mazzeo AT, Campo GM, Ferlito M, Minutoli L, Bazzani C, Bertolini A, Caputi AP, Squadrito F 2001 Oxidative stress causes nuclear factor $-\kappa \mathrm{B}$ activation in acute hypovolemic hemorrhagic shock. Free Radic Biol Med 30:1055-1066

30. Zhang DX, Zou AP, Li PL 2001 Adenosine diphosphate ribose dilates bovine coronary small arteries through apyrase- and $5^{\prime}$-nucleotidase-mediated metabolism. J Vasc Res 38:64-72

31. Rüdiger M, Wissel H, Ochs M, Burkhardt W, Proquitté H, Wauer RR, Stevens P, Rüstow B 2003 Perfluorocarbons are taken up by isolated type II pneumocytes and influence its liquid synthesis and secretion. Crit Care Med 31:1190-1196

32. Coombes BK, Mahony JB 2002 Identification of MEK- and phosphoinositide 3-kinase-dependent signaling as essential events during Chlamydia pneumoniae invasion of Hep2 cells. Cell Microbiol 4:447-460

33. Wissel H, Müller T, Rüdiger M, Krüll M, Wauer RR 2005 Contact of Chlamydophila pneumoniae with type II cell triggers activation of calcium-mediated NF- $\kappa$ B pathway. Biochim Biophys Acta 1743:37-48

34. Puolakkainen M, Kuo CC, Campbell LA 2005 Chlamydia pneumoniae uses the mannose 6-phosphate/insulin-like growth factor 2 receptor for infection of endothelial cells. Infect Immun 73:4620-4625

35. Prebeck S, Kirschning C, Durr S, da Costa C, Donath B, Brand K, Redecke V, Wagner H, Miethke T 2001 Predominant role of toll-like receptor 2 versus 4 in Chlamydia pneumoniae-induced activation of dendritic cells. J Immunol 15:33163323

36. Sasu S, LaVerda D, Qureshi N, Golenbock DT, Beasley D 2001 Chlamydia pneumoniae and chlamydial heat shock protein 60 stimulate proliferation of human vascular smooth muscle cells via toll-like receptor 4 and p44/p42 mitogen-activated protein kinase activation. Circ Res 89:244-250

37. Costa CP, Kirschning CJ, Busch D, Durr S, Jennen L, Heinzmann U, Prebeck S, Wagner H, Miethke T 2002 Role of chlamydial heat shock protein 60 in the stimulation of innate immune cells by Chlamydia pneumoniae. Eur J Immunol 32:2460-2470

38. Da Costa CU, Wantia N, Kirschning CJ, Busch DH, Rodriguez N, Wagner H, Miethke T 2004 Heat shock protein 60 from Chlamydia pneumoniae elicits an unusual set of inflammatory responses via Toll-like receptor 2 and 4 in vivo. Eur J Immunol 34:2874-2884

39. Rüdiger M, Köpke U, Prösch S, Rauprich P, Wauer RR, Herting E 2001 Effects of perfluorocarbons and perfluorocarbons/surfactant-emulsions on growth and viability of group B streptococci and Escherichia coli. Crit Care Med 29:1786-1791 